\title{
Surgical therapy for pulmonary metastasis of breast cancer
}

\author{
Junichi Soh $^{1}$, Yoshifumi Komoike ${ }^{2}$, Tetsuya Mitsudomi ${ }^{1}$ \\ ${ }^{1}$ Division of Thoracic Surgery, Department of Surgery, ${ }^{2}$ Division of Breast and Endocrine Surgery, Department of Surgery, Kindai University Faculty \\ of Medicine, Osaka-sayama, Osaka, Japan \\ Contributions: (I) Conception and design: J Soh; (II) Administrative support: J Soh; (III) Provision of study materials or patients: J Soh; (IV) Collection \\ and assembly of data: J Soh; (V) Data analysis and interpretation: J Soh; (VI) Manuscript writing: All authors; (VII) Final approval of manuscript: All \\ authors. \\ Correspondence to: Junichi Soh, MD, PhD. Division of Thoracic Surgery, Department of Surgery, Kindai University Faculty of Medicine, 377-2 \\ Ohno-higashi, Osaka-sayama, Osaka 589-8511, Japan. Email: drjsou7@gmail.com.
}

\begin{abstract}
Metastatic breast cancer $(\mathrm{MBC})$ is a disease with heterogeneous manifestations that arise from a variety of modes of spread from the primary disease. The lung is a common site of metastasis from breast cancer. A solitary lung nodule appearing on radiological examination following breast cancer treatment is likely to be diagnosed as pulmonary metastasis from breast cancer. However, the reported final pathological diagnoses include primary lung cancer and $\mathrm{MBC}$ in approximately $48-67 \%$ and $23-43 \%$ of cases, respectively. Moreover, some pulmonary metastases of breast cancer have radiological and histological characteristics similar to those of primary lung cancer. Thus, the differential diagnosis of a solitary lung nodule after treatment of breast cancer is challenging. Oligometastatic disease (OMD) is characterized by solitary or limited numbers of detectable metastatic lesions. OMD in the lung from colorectal cancer can be considered for locoregional treatments either alone or in combination with systemic therapy. In MBC patients, the indication for locoregional treatments for pulmonary metastasis is controversial, whereas surgical intervention can be performed to obtain tissue for histological and molecular confirmation and occasionally for curative intent in selected MBC patients. While several retrospective studies have examined the clinical impact of pulmonary metastasectomy (PM) in MBC patients, no prospective randomized trials have been conducted. Our systematic review of PM in MBC patients found that PM might offer a survival advantage in selected MBC patients with a long disease-free interval (DFI), small number of pulmonary metastases, complete resection, and/or hormone receptor positivity. Metastases are usually detected by radiological examinations such as computed tomography (CT) and positron emission tomography-CT. The detectability of these radiological examinations mainly depends on tumor size (size-dependent manner). By contrast, the amount of circulating tumor DNA (ctDNA) released by apoptotic or necrotic tumor cells depends on the tumor burden in the whole body, regardless of radiological detectability (dose-dependent manner). Since ctDNA assays reportedly reveal residual disease several weeks earlier than radiologic imaging does, monitoring for radiological tumor size and ctDNA concentration during the clinical course may help to inform the indication for local treatment in patients with $\mathrm{MBC}$ and may improve their clinical outcomes. This article reviewed the current status of PM in MBC patients with pulmonary metastasis and discussed future perspectives.
\end{abstract}

Keywords: Pulmonary metastasectomy (PM); oligometastasis; differential diagnosis

Submitted Feb 15, 2020. Accepted for publication Mar 09, 2020.

doi: $10.21037 /$ tcr.2020.03.63

View this article at: http://dx.doi.org/10.21037/tcr.2020.03.63 


\section{Introduction}

Metastatic breast cancer (MBC) encompasses primary breast cancers with distant metastasis and recurrence after surgery. In general, cure is rarely achieved in patients with MBC; thus, systemic therapy is the standard of care for this disease. Although recent advances in systemic therapies have led to improved survival in patients with MBC (1-3), their clinical outcomes remain unsatisfactory. The elucidation of patient subgroups that may benefit from different treatment strategies is of great interest. The lung is an important site of metastasis from breast cancer (4-6). Multiple pulmonary metastases are commonly observed in patients with $\mathrm{MBC}$; however, a solitary or limited number of metastases may also be detected (4). Cases in which a solitary lung nodule is detected in patients previously treated for breast cancer require histological confirmation for differential diagnosis and treatment strategy because this manifestation represents something other than recurrent disease such as primary lung cancer or benign lung tumor $(7,8)$. Women treated for breast cancer have an increased risk of second malignancies, including lung cancer, compared to the general population $(9,10)$. Most pulmonary metastases show typical radiological features of smooth and ovoid margins but occasionally show radiological signs similar to those of primary lung adenocarcinomas, such as margin notching or irregularity (8). The histological diagnosis of $\mathrm{MBC}$ and primary lung adenocarcinoma is also difficult (11).

Oligometastatic disease (OMD) is characterized by a solitary or limited number of detectable metastatic lesions $(12,13)$. Patients with OMD may receive locoregional treatments either alone or in combination with systemic therapy with curative intent (14). In colorectal cancer, the clinical practice guidelines from the European Society for Medical Oncology (ESMO) (15) and National Comprehensive Cancer Network (NCCN) (16) recommend surgical intervention or other locoregional treatments in patients with "resectable" OMD. The reported 5-year survival rates after surgical intervention range from $20 \%$ to $45 \%$ for complete resection of liver or pulmonary metastasis. In MBC (15). OMD accounts for $1-10 \%$ of all newly diagnosed patients $(17,18)$, and locoregional treatment remains controversial in this population.

This review presents and discusses available data on $M B C$ of the lung for differential diagnosis and local treatment, especially surgical treatment, which may be associated with improved survival in select patients.

\section{Clinical features of pulmonary metastasis in breast cancer}

At the time of diagnosis, only $5-10 \%$ of breast cancer patients have distant metastasis $(19,20)$. However, more than $30 \%$ of breast cancer patients experience recurrence (6). The bone, liver, lung, and brain are common sites of distant metastasis in breast cancer $(21,22)$. At diagnosis, most pulmonary metastases are asymptomatic; however, progression may cause serious conditions and symptoms such as cough, hemoptysis, pleural effusion, and pulmonary dysfunction, which profoundly affect patients' quality of life and survival (6). There is a need to establish better treatment strategies for pulmonary metastasis in breast cancer.

The reported incidence of pulmonary metastasis in patients with breast cancer ranges from $7 \%$ to $24 \%$ according to histological and molecular subtypes (23). Visceral metastasis such as pulmonary metastasis preferentially occurs in triple-negative breast cancer (TNBC) patients, while bone metastasis is frequent in non-TNBC patients (23-26). The incidence of pulmonary metastasis can reach $40 \%$ in TNBC and $20 \%$ in non-TNBC patients (26). Different subtypes exhibit distinctive behavior concerning the sites of distant metastasis (6).

\section{Management of a solitary lung nodule after first breast cancer}

Solitary lung nodules observed after breast cancer treatment are traditionally considered to represent metastasis from the breast (27). It is difficult to completely avoid misdiagnosis of a solitary lung nodule in patients after treatment of the first breast cancer, and inappropriate treatment is thus possible (28). Although the radiological features on computed tomography (CT) imaging usually differ between primary lung cancer and metastatic lung tumor, differential diagnosis using radiological examination can be misleading because some pulmonary metastases have an irregularlyshaped appearance similar to that of primary lung cancer (8). The final pathological diagnosis of solitary lung nodules include primary lung cancer, $\mathrm{MBC}$, and benign tumor in $48-67 \%, 23-43 \%$, and $5-10 \%$ of cases, respectively $(7,27,29)$. Therefore, in patients with a solitary lung nodule and a history of breast cancer, differentiation of MBC lung 
nodule from primary lung cancer, benign lung tumor, and metastasis from other types of cancer is recommended to determine the treatment strategy. Among invasive methods, surgical intervention is the most powerful approach to provide sufficient tissue for histological confirmation along with the determination of hormone receptor expression and human epidermal growth factor receptor 2 (Her2/ neu) statuses. Transbronchoscopic lung biopsy or CTguided lung biopsy might also be selected based on the tumor location and the accessibility of transbronchial or percutaneous approaches. Since both breast and lung adenocarcinomas show similar histological findings such as secretory-featured cytoplasm, stromal fibrosis, and growth along the alveolar septa (11), pathological diagnosis by hematoxylin-eosin staining, including intraoperative rapid pathological diagnosis, is challenging. Therefore, immunohistochemical analyses of TTF-1, HER2 (27) or MGB1 (11) are useful for the differential diagnosis of pulmonary metastasis of $\mathrm{MBC}$ and primary lung cancer.

Similar to other malignancies, the incidence of second primary neoplasms after breast cancer treatment is increasing (30). A cohort study of 17,745 women who received breast cancer treatment observed 2,370 secondary malignancies during follow-up with a 15 -year cumulative incidence of second malignancies of 1.807 per 100,000 [95\% confidence interval (CI), 1.729-1.884] after breast cancer treatment (9). The crude incidence rates of this cohort were significantly higher than those of the general population for several malignancies, including contralateral breast cancer [standard incidence rate (SIR), 2.96; 95\% CI, 2.8-3.1] and lung cancer (SIR, 1.39; 95\% CI, 1.1-1.7). Lung cancers account for $5 \%$ of second primary cancers after breast cancer (31).

Lorigan et al. reviewed to determine risk factors of lung cancer after treatment of breast cancer (32). A populationbased study of the Surveillance, Epidemiology and End Results (SEER) program found that adjuvant radiotherapy after mastectomy increased the relative risk of lung cancer of 1.5 (95\% CI, 1.3-2.0) comparing patients underwent a radical mastectomy alone (33). Other reports have also reported that radiotherapy for breast cancer increased the risk of second non-breast cancer such as cancer of the lung, esophagus and sarcomas at exposed sites $(9,34)$.

\section{Surgical procedures of pulmonary metastasectomy (PM)}

PM requires resection of all detectable lung nodules. Partial or sublober resection is usually performed as PM; however, lobectomy or more extensive resection is occasionally performed to avoid residual tumor (35).

Mediastinal lymph node (LN) dissection is not commonly performed in patients with MBC (35), but lobectomy with mediastinal LN dissection can be performed if primary lung cancer is likely to be considered. Intrathoracic LN metastasis occurs in 39\% of patients with thoracic metastasis from breast cancers (36), 13-44\% of patients with pulmonary metastasis from colorectal cancers $(37,38)$, and $35 \%$ of patients with renal cell carcinomas (39). However, no randomized controlled trials have been conducted to determine the therapeutic effect of $\mathrm{LN}$ dissection in these patients, and the indications for $\mathrm{LN}$ dissection remain controversial (35).

During surgery, pulmonary metastasis is usually detected by manual palpation by the surgeon's fingers or the use of surgical instruments. Localization of target lesions can be difficult if they are small, multiple, and/or centrally located. In these cases, multiple localization techniques, including CT-guided use of a short hook wire (40) and bronchoscopic multispot dye-marking (41), have also been applied. Using these techniques and/or manual palpitation, the videoassisted thoracoscopic approach can also be performed for PM (42). However, an open thoracotomy is sometimes needed for more elaborate exploration to confirm the presence of metastasis by palpation and to perform extended resections of large lesions.

\section{Clinical impact of PM for breast cancer}

Regarding patient selection for PM, in general, it is important that (I) the primary disease site is controlled, (II) there are no other systemic metastases, or if present, they are actively managed, and (III) an adequate disease-free interval (DFI) is present to confirm "oligometastatic" disease $(35,43)$. In most MBC patients, $\mathrm{PM}$ is considered for histological confirmation along with the determination of molecular status, and the role of local treatment is limited (35). Yhim et al. retrospectively investigated the clinical outcomes of consecutive recurrent breast cancer patients with a limited number of isolated pulmonary metastases (less than 4), who received PM followed by systemic treatment (PM group) or systemic treatment alone (non-PM group), during 19972007 (44). The authors reported a significantly longer 4-year OS in the PM group than that in the non-PM group $(82.1 \%$ vs. $31.6 \%, \mathrm{P}=0.001)$.

Our systematic review assessed survival and prognostic 


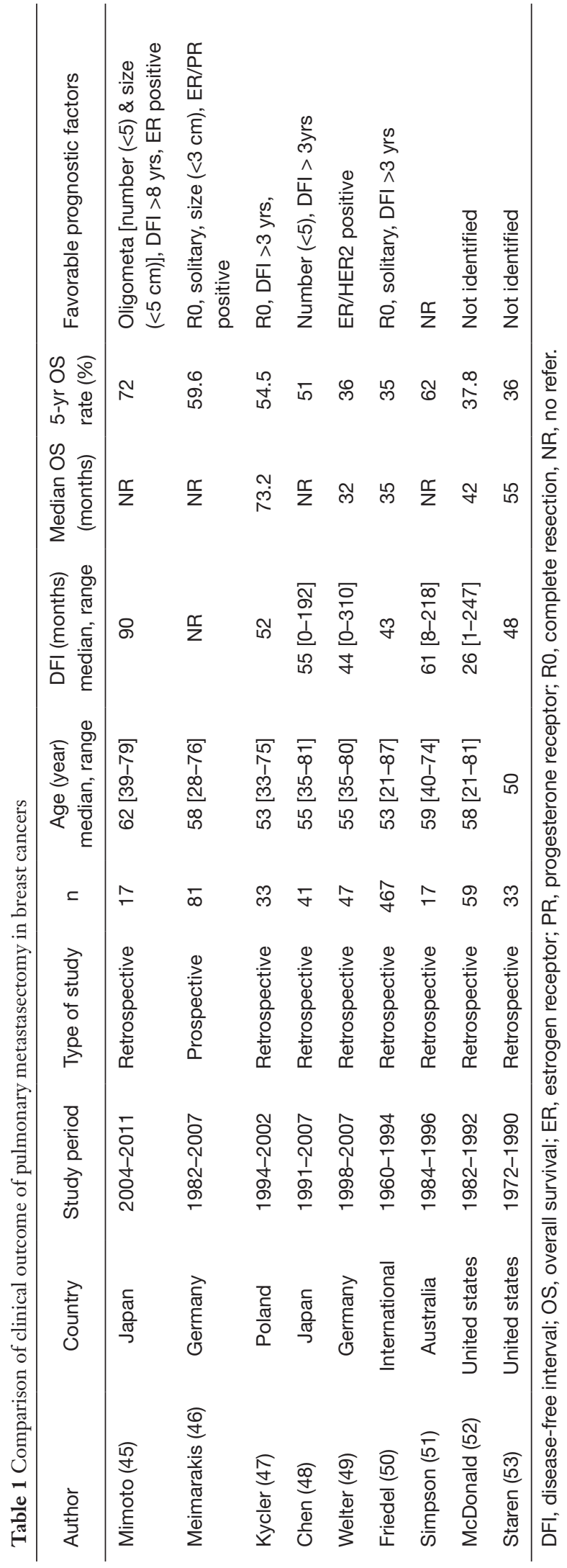

factors for PM in patients with pulmonary MBC. An electronic search of PubMed, complemented by manual searches of the English literature, identified eligible studies using the keywords ["pulmonary metastasectomy" AND "breast cancer"], ["lung metastasectomy" AND "breast cancer"], or ["pulmonary resection" AND "metastatic breast cancer"]. After excluding inadequate literature such as case reports, those including other malignancies, and review articles, nine studies were retrieved (45-53) (Table 1). The patients' age at PM diagnosis ranged from 50 to 62 years. The DFI, defined as the interval between surgery for primary breast cancer and the appearance of pulmonary metastases, was 26 to 90 months. The 5 -year survival rate in MBC patients undergoing PM was $35-72 \%$. The frequently reported significant favorable prognostic factors were DFI (four studies; $>3$ or 8 years), number of pulmonary metastases (four studies; 1 or $<5$ ), complete resection (three studies; R0), and the hormone receptor status of the metastases (three studies: positive). This evidence suggests that PM may be a treatment option in selected patients with MBC; however, prospective randomized trials are necessary to establish an optimal treatment strategy.

\section{Monitoring of circulating tumor DNA (ctDNA) levels}

A precise determination of disease status (limited or multiple metastases) is important to consider the indication for local treatment in patients with MBC. Disease status is usually diagnosed by radiological examinations such as CT and PET/ CT. The detectability of these radiological examinations depends on the tumor size (size-dependent manner) (Figure 1). Circulating cell-free tumor DNA (ctDNA) is released by apoptotic or necrotic tumor cells (54). Using sensitive molecular assays, cancer-specific aberrations can be detected in the ctDNA and used for cancer screening, therapeutic target identification, real-time therapy monitoring, and early diagnosis (54,55). ctDNA levels depend on the tumor burden in the whole body (dose-dependent manner) (Figure 1), and changes in ctDNA levels are associated with tumor volume (56). In clinical course, ctDNA dynamics can be used as a surrogate marker for relapse and metastasis in patients with lung (57) and breast $(58,59)$ cancers. Importantly, ctDNA analysis can detect incipient recurrence earlier than radiological diagnostic modalities with an average lead time of 10 months (range, 2-15 months) (60).

In patients with a limited number of radiologically detectable metastases (solitary or a few), ctDNA levels 


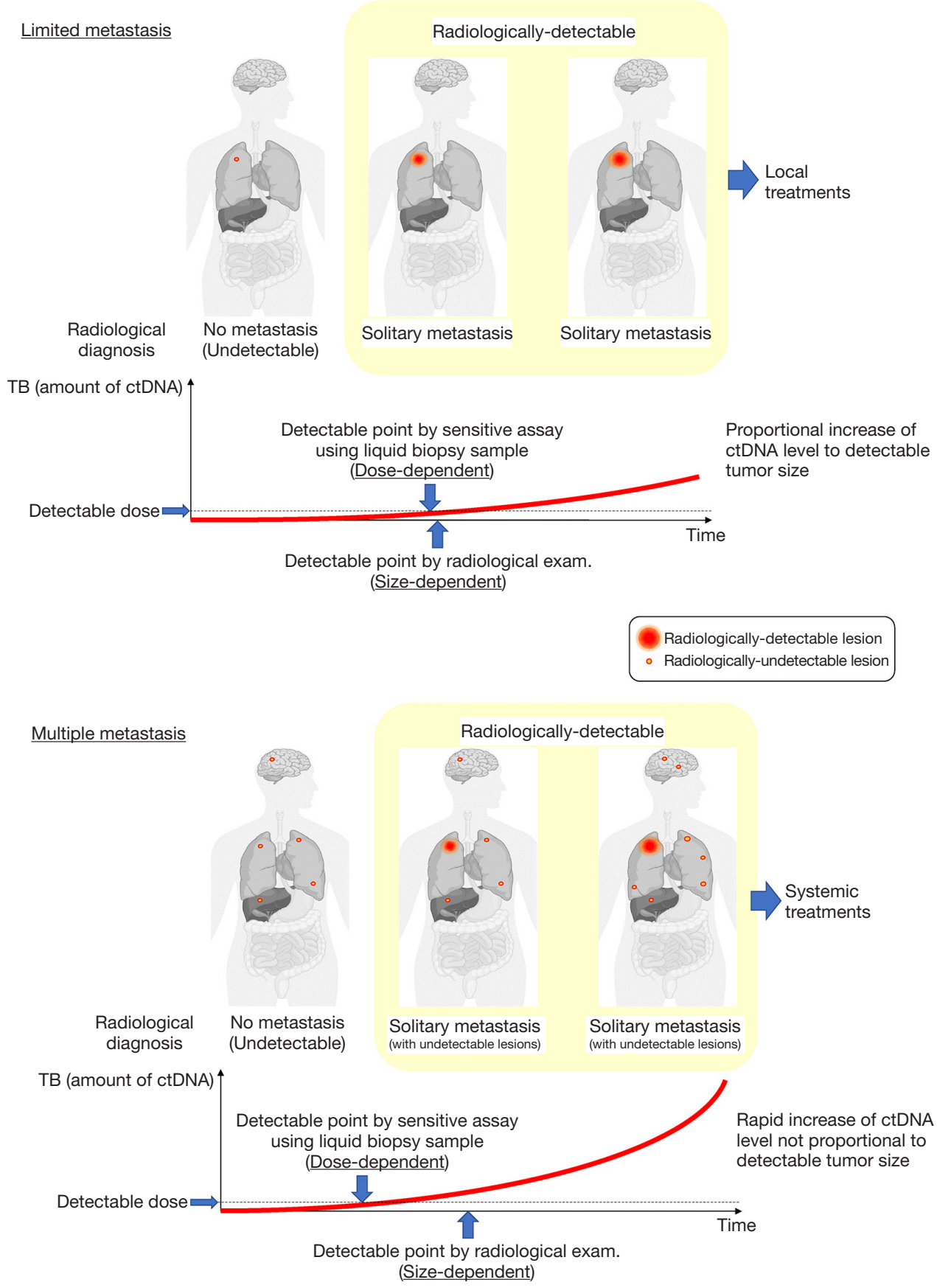

Figure 1 Tumor burden and radiological detectability in limited or multiple metastasis. Radiological detectability is mainly affected by tumor size (size-dependent), regardless of tumor burden (TB) in whole body. By contrast, the amount of circulating tumor DNA (ctDNA) is affected by TB in whole body (dose-dependent), regardless of the size of a maximum tumor. In clinical course, monitoring of radiological size and ctDNA amount may help to distinguish limited metastasis from multiple metastasis by comparing the rate of increase in tumor size with the rate of increase of ctDNA. Furthermore, dynamics of ctDNA after local treatment is useful to consider the indication of adjuvant therapy in MBC patients. Exam., examination; MBC, metastatic breast cancer. 
increase in proportion to the growth rate of radiologically detectable tumors (Figure 1). By contrast, in patients with multiple undetectable metastases and a limited number of radiologically detectable metastases, ctDNA can be detected at an earlier point of the clinical course and ctDNA levels continue to increase regardless of the growth rate of a radiologically detectable tumor. Monitoring of ctDNA levels may help to determine the treatment strategies for patients with MBC.

\section{Future perspectives}

Regarding local treatments other than surgery, remarkable advances have been made in radiotherapy, including the development of stereotactic ablative body radiotherapy (SABR) and thermal ablation therapies including radiofrequency ablation, microwave, and cryotherapy (61-63). The usefulness of these methodologies has been reported for lesions that are difficult to resect. SABR or thermal ablation can benefit patients with pulmonary OMD, particularly those at a high risk for surgery or those who refuse surgery (35).

Currently, various novel anticancer drugs such as cytotoxic cancer drugs, and molecular-targeted drugs, and immune checkpoint inhibitors are being developed. Various ongoing clinical trials are assessing these drugs in monotherapy or combination therapy (64). Since treatment strategies for MBC patients are rapidly changing, the indications for PM in MBC patients should be discussed by multidisciplinary teams including respiratory surgeons, breast cancer physicians, oncologists, and radiation therapists.

\section{Conclusions}

Differential diagnosis of a solitary lung tumor is difficult in patients with a history of breast cancer treatment. Some pulmonary metastases in breast cancer have radiological and histological characteristics similar to those of primary lung cancer. In MBC patients with pulmonary metastasis, selected MBC patients with a small number of lung tumors, long DFI, or hormone receptor positivity may benefit from the resection of pulmonary metastasis; however, the selection criteria have not been clearly defined. Using novel technologies and modalities, patient selection for individualized treatment options will help to establish a "cure" for MBC patients.

\section{Acknowledgments}

Funding: None.

\section{Footnote}

Provenance and Peer Review: This article was commissioned by the Guest Editors (Tadahiko Shien and Kaori Terata) for the series "Loco regional therapy for metastatic breast cancer" published in Translational Cancer Research. The article was sent for external peer review organized by the Guest Editors and the editorial office.

Conflicts of Interest: All authors have completed the ICMJE uniform disclosure form (available at http://dx.doi. org/10.21037/tcr.2020.03.63). The series "Loco-regional therapy for metastatic breast cancer" was commissioned by the editorial office without any funding or sponsorship. TM reports grants and personal fees from Pfizer, grants and personal fees from Boehringer Ingelheim, grants and personal fees from MSD, grants and personal fees from Chugai, grants and personal fees from Taiho, grants and personal fees from Eli Lilly, grants and personal fees from Ono Pharmaceutical, grants from Daiichi-Sankyo, personal fees from Bristol-Myers Squibb, personal fees from Astra Zeneca, personal fees from Thermofisher, personal fees from Roche Diagnostics, outside the submitted work. The authors have no conflicts of other interest to declare.

Ethical Statement: The authors are accountable for all aspects of the work in ensuring that questions related to the accuracy or integrity of any part of the work are appropriately investigated and resolved.

Open Access Statement: This is an Open Access article distributed in accordance with the Creative Commons Attribution-NonCommercial-NoDerivs 4.0 International License (CC BY-NC-ND 4.0), which permits the noncommercial replication and distribution of the article with the strict proviso that no changes or edits are made and the original work is properly cited (including links to both the formal publication through the relevant DOI and the license). See: https://creativecommons.org/licenses/by-nc-nd/4.0/.

\section{References}

1. Andre F, Slimane K, Bachelot T, et al. Breast cancer with 
synchronous metastases: trends in survival during a 14year period. J Clin Oncol 2004;22:3302-8.

2. Chia SK, Speers CH, D'Yachkova Y, et al. The impact of new chemotherapeutic and hormone agents on survival in a population-based cohort of women with metastatic breast cancer. Cancer 2007;110:973-9.

3. Caswell-Jin JL, Plevritis SK, Tian L, et al. Change in Survival in Metastatic Breast Cancer with Treatment Advances: Meta-Analysis and Systematic Review. JNCI Cancer Spectr 2018;2:pky062.

4. Schlappack OK, Baur M, Steger G, et al. The clinical course of lung metastases from breast cancer. Klin Wochenschr 1988;66:790-5.

5. Gao D, Du J, Cong L, et al. Risk factors for initial lung metastasis from breast invasive ductal carcinoma in stages I-III of operable patients. Jpn J Clin Oncol 2009;39:97-104.

6. Jin L, Han B, Siegel E, et al. Breast cancer lung metastasis: Molecular biology and therapeutic implications. Cancer Biol Ther 2018;19:858-68.

7. Casey JJ, Stempel BG, Scanlon EF, et al. The solitary pulmonary nodule in the patient with breast cancer. Surgery 1984;96:801-5.

8. Miyazaki K, Satoh H, Watanabe H, et al. Sole metastatic pulmonary nodules from breast cancer simulating primary lung adenocarcinoma: Two case reports. Mol Clin Oncol 2017;6:425-7.

9. Bazire L, De Rycke Y, Asselain B, et al. Risks of second malignancies after breast cancer treatment: Long-term results. Cancer Radiother 2017;21:10-5.

10. Milano MT, Strawderman RL, Venigalla S, et al. Nonsmall-cell lung cancer after breast cancer: a populationbased study of clinicopathologic characteristics and survival outcomes in 3529 women. J Thorac Oncol 2014;9:1081-90.

11. Koga T, Horio Y, Mitsudomi T, et al. Identification of MGB1 as a marker in the differential diagnosis of lung tumors in patients with a history of breast cancer by analysis of publicly available SAGE data. J Mol Diagn 2004;6:90-5.

12. Hellman S, Weichselbaum RR. Oligometastases. J Clin Oncol 1995;13:8-10.

13. Pagani O, Senkus E, Wood W, et al. International guidelines for management of metastatic breast cancer: can metastatic breast cancer be cured? J Natl Cancer Inst 2010;102:456-63

14. Kobayashi T, Ichiba T, Sakuyama T, et al. Possible clinical cure of metastatic breast cancer: lessons from our 30-year experience with oligometastatic breast cancer patients and literature review. Breast Cancer 2012;19:218-37.

15. Van Cutsem E, Cervantes A, Nordlinger B, et al. Metastatic colorectal cancer: ESMO Clinical Practice Guidelines for diagnosis, treatment and follow-up. Ann Oncol 2014;25 Suppl 3:iii1-9.

16. National Comprehensive Cancer Network. Colon Cancer (Version 1.2020). Available online: https://www.nccn. org/professionals/physician_gls/pdf/colon.pdf. Accessed February 11, 2019.

17. Hortobagyi GN. Can we cure limited metastatic breast cancer? J Clin Oncol 2002;20:620-3.

18. Hanrahan EO, Broglio KR, Buzdar AU, et al. Combined-modality treatment for isolated recurrences of breast carcinoma: update on 30 years of experience at the University of Texas M.D. Anderson Cancer Center and assessment of prognostic factors. Cancer 2005;104:1158-71.

19. Cardoso F, Costa A, Norton L, et al. 1st International consensus guidelines for advanced breast cancer (ABC 1). Breast 2012;21:242-52.

20. Gupta GP, Massague J. Cancer metastasis: building a framework. Cell 2006;127:679-95.

21. Largillier R, Ferrero JM, Doyen J, et al. Prognostic factors in 1,038 women with metastatic breast cancer. Ann Oncol 2008;19:2012-9.

22. Chang J, Clark GM, Allred DC, et al. Survival of patients with metastatic breast carcinoma: importance of prognostic markers of the primary tumor. Cancer 2003;97:545-53.

23. Kennecke H, Yerushalmi R, Woods R, et al. Metastatic behavior of breast cancer subtypes. J Clin Oncol 2010;28:3271-7.

24. Liedtke C, Mazouni C, Hess KR, et al. Response to neoadjuvant therapy and long-term survival in patients with triple-negative breast cancer. J Clin Oncol 2008;26:1275-81.

25. Dent R, Hanna WM, Trudeau M, et al. Pattern of metastatic spread in triple-negative breast cancer. Breast Cancer Res Treat 2009;115:423-8.

26. Foulkes WD, Smith IE, Reis-Filho JS. Triple-negative breast cancer. N Engl J Med 2010;363:1938-48.

27. Rena O, Papalia E, Ruffini E, et al. The role of surgery in the management of solitary pulmonary nodule in breast cancer patients. Eur J Surg Oncol 2007;33:546-50.

28. Kong FW, Wang H, Zhang H, et al. Second primary lung cancer after a first breast cancer: a case report and critical literature review. International Journal of Clinical and Experimental Medicine 2018;11:1049-54. 
29. Tanaka K, Shimizu K, Ohtaki Y, et al. Diagnosis and surgical resection of solitary pulmonary nodules in patients with breast cancer. Mol Clin Oncol 2013;1:117-23.

30. Levi F, Randimbison L, Rafael BM, et al. Second primary cancers in the Vaud and Neuchatel Cancer Registries. Eur J Cancer Prev 2015;24:150-4.

31. Schonfeld SJ, Curtis RE, Anderson WF, et al. The risk of a second primary lung cancer after a first invasive breast cancer according to estrogen receptor status. Cancer Causes Control 2012;23:1721-8.

32. Lorigan P, Califano R, Faivre-Finn C, et al. Lung cancer after treatment for breast cancer. Lancet Oncol 2010;11:1184-92.

33. Zablotska LB, Neugut AI. Lung carcinoma after radiation therapy in women treated with lumpectomy or mastectomy for primary breast carcinoma. Cancer 2003;97:1404-11.

34. Santos AM, Marcu LG, Wong CM, et al. Risk estimation of second primary cancers after breast radiotherapy. Acta Oncol 2016;55:1331-7.

35. Handy JR, Bremner RM, Crocenzi TS, et al. Expert Consensus Document on Pulmonary Metastasectomy. Ann Thorac Surg 2019;107:631-49.

36. Kreisman H, Wolkove N, Finkelstein HS, et al. Breast cancer and thoracic metastases: review of 119 patients. Thorax 1983;38:175-9.

37. Hamaji M, Cassivi SD, Shen KR, et al. Is lymph node dissection required in pulmonary metastasectomy for colorectal adenocarcinoma? Ann Thorac Surg 2012;94:1796-800.

38. Renaud S, Alifano M, Falcoz PE, et al. Does nodal status influence survival? Results of a 19-year systematic lymphadenectomy experience during lung metastasectomy of colorectal cancer. Interact Cardiovasc Thorac Surg 2014;18:482-7.

39. Winter H, Meimarakis G, Angele MK, et al. Tumor infiltrated hilar and mediastinal lymph nodes are an independent prognostic factor for decreased survival after pulmonary metastasectomy in patients with renal cell carcinoma. J Urol 2010;184:1888-94.

40. Iguchi T, Hiraki T, Gobara H, et al. CT fluoroscopyguided preoperative short hook wire placement for small pulmonary lesions: evaluation of safety and identification of risk factors for pneumothorax. Eur Radiol 2016;26:114-21.

41. Sato M, Omasa M, Chen F, et al. Use of virtual assisted lung mapping (VAL-MAP), a bronchoscopic multispot dye-marking technique using virtual images, for precise navigation of thoracoscopic sublobar lung resection. J
Thorac Cardiovasc Surg 2014;147:1813-9.

42. Hornbech K, Ravn J, Steinbruchel DA. Current status of pulmonary metastasectomy. Eur J Cardiothorac Surg 2011;39:955-62.

43. Thomford NR, Woolner LB, Clagett OT. The Surgical Treatment of Metastatic Tumors in the Lungs. J Thorac Cardiovasc Surg 1965;49:357-63.

44. Yhim HY, Han SW, Oh DY, et al. Prognostic factors for recurrent breast cancer patients with an isolated, limited number of lung metastases and implications for pulmonary metastasectomy. Cancer 2010;116:2890-901.

45. Mimoto R, Kobayashi T, Imawari Y, et al. Clinical relevance and low tumor-initiating properties of oligometastatic breast cancer in pulmonary metastasectomy. Breast Cancer Res Treat 2014;147:317-24.

46. Meimarakis G, Ruttinger D, Stemmler J, et al. Prolonged overall survival after pulmonary metastasectomy in patients with breast cancer. Ann Thorac Surg 2013;95:1170-80.

47. Kycler W, Laski P. Surgical approach to pulmonary metastases from breast cancer. Breast J 2012;18:52-7.

48. Chen F, Fujinaga T, Sato K, et al. Clinical features of surgical resection for pulmonary metastasis from breast cancer. Eur J Surg Oncol 2009;35:393-7.

49. Welter S, Jacobs J, Krbek T, et al. Pulmonary metastases of breast cancer. When is resection indicated? Eur J Cardiothorac Surg 2008;34:1228-34.

50. Friedel G, Pastorino U, Ginsberg RJ, et al. Results of lung metastasectomy from breast cancer: prognostic criteria on the basis of 467 cases of the International Registry of Lung Metastases. Eur J Cardiothorac Surg 2002;22:335-44.

51. Simpson R, Kennedy C, Carmalt H, et al. Pulmonary resection for metastatic breast cancer. Aust N Z J Surg 1997;67:717-9.

52. McDonald ML, Deschamps C, Ilstrup DM, et al. Pulmonary resection for metastatic breast cancer. Ann Thorac Surg 1994;58:1599-602.

53. Staren ED, Salerno C, Rongione A, et al. Pulmonary resection for metastatic breast cancer. Arch Surg 1992;127:1282-4.

54. Alix-Panabieres C, Pantel K. Clinical Applications of Circulating Tumor Cells and Circulating Tumor DNA as Liquid Biopsy. Cancer Discov 2016;6:479-91.

55. Chen $M$, Zhao H. Next-generation sequencing in liquid biopsy: cancer screening and early detection. Hum Genomics 2019;13:34.

56. Scholer LV, Reinert T, Orntoft MW, et al. Clinical Implications of Monitoring Circulating Tumor DNA in Patients with Colorectal Cancer. Clin Cancer Res 
2017;23:5437-45.

57. Abbosh C, Birkbak NJ, Wilson GA, et al. Phylogenetic ctDNA analysis depicts early-stage lung cancer evolution. Nature 2017;545:446-51.

58. Hrebien S, Citi V, Garcia-Murillas I, et al. Early ctDNA dynamics as a surrogate for progression-free survival in advanced breast cancer in the BEECH trial. Ann Oncol 2019;30:945-52.

59. Coombes RC, Page K, Salari R, et al. Personalized Detection of Circulating Tumor DNA Antedates Breast Cancer Metastatic Recurrence. Clin Cancer Res 2019;25:4255-63.

60. Reinert T, Scholer LV, Thomsen R, et al. Analysis of circulating tumour DNA to monitor disease burden following colorectal cancer surgery. Gut 2016;65:625-34.
61. de Baere T, Auperin A, Deschamps F, et al. Radiofrequency ablation is a valid treatment option for lung metastases: experience in 566 patients with 1037 metastases. Ann Oncol 2015;26:987-91.

62. Matsui Y, Hiraki T, Gobara H, et al. Long-term survival following percutaneous radiofrequency ablation of colorectal lung metastases. J Vasc Interv Radiol 2015;26:303-10; quiz 11.

63. Palussiere J, Catena V, Buy X. Percutaneous thermal ablation of lung tumors - Radiofrequency, microwave and cryotherapy: Where are we going? Diagn Interv Imaging 2017;98:619-25.

64. Lyons TG. Targeted Therapies for Triple-Negative Breast Cancer. Curr Treat Options Oncol 2019;20:82.
Cite this article as: Soh J, Komoike Y, Mitsudomi T. Surgical therapy for pulmonary metastasis of breast cancer. Transl Cancer Res 2020;9(8):5044-5052. doi: 10.21037/tcr.2020.03.63 